\title{
Longitudinal Adherence With Fecal Occult Blood Test Screening in Community Practice
}

\author{
Joshua J. Fenton, MD, MPH ${ }^{1,2}$ \\ Joann G. Elmore, $M D, M P H^{3,4}$ \\ Diana S. M. Buist, PbD, MPH \\ Robert J. Reid, $M D, P b D^{6}$ \\ Daniel J. Tancredi, $\mathrm{PbD}^{2,7}$ \\ Laura-Mae Baldwin, MD, MPH ${ }^{8}$ \\ 'Department of Family and Community \\ Medicine, University of California, Davis, \\ Sacramento, California \\ ${ }^{2}$ Center for Healthcare Policy and Research, \\ University of California, Davis, Sacra- \\ mento, California \\ ${ }^{3}$ Department of Medicine, University of \\ Washington, Seattle, Washington \\ ${ }^{4}$ Department of Epidemiology, University \\ of Washington, Seattle, Washington \\ ${ }^{5}$ Group Health Research Institute, Group \\ Health Cooperative, Seattle, Washington \\ ${ }^{6}$ Department of Preventive Medicine, \\ Group Health Cooperative, Seattle, \\ Washington \\ ${ }^{7}$ Department of Pediatrics, University of \\ California, Davis, Sacramento, California \\ ${ }^{8}$ Department of Family Medicine, Univer- \\ sity of Washington, Seattle, Washington
}

Conflicts of interest: none reported

\section{CORRESPONDING AUTHOR}

Joshua Fenton, MD, MPH

Department of Family and Community

Medicine

University of California, Davis

4860 Y St, Suite 2300

Sacramento, CA 95817

Joshua.fenton@ucdmc.ucdavis.edu

\begin{abstract}
PURPOSE Although screening with fecal occult blood testing (FOBT) reduces colorectal cancer (CRC) mortality, its effectiveness may diminish if patients do not adhere with repeated screenings. Among patients who had previously engaged in FOBT screening, we assessed subsequent adherence with FOBT screening.
\end{abstract}

METHODS We assessed longitudinal adherence with biennial FOBT screening (every other year) within a cohort of patients enrolled in an integrated Washington State health plan. Among 11,110 patients who participated in FOBT screening during a 2-year baseline period (2000-2001), we ascertained CRC screening use during a subsequent 2-year observation period (2002-2003). We used multinomial logistic regression to identify patient characteristics associated with higher incidence of repeat CRC screening (with or without FOBT) relative to patients who received no CRC screening.

RESULTS Despite prior participation in FOBT screening, less than one-half of patients (44.4\%; 95\% Cl, 42.9\%-45.8\%) completed FOBT screening during the 2-year observation period. Although $8.8 \%$ of patients (95\% Cl, 8.0\%-9.7\%) received other $\mathrm{CRC}$ tests without $\mathrm{FOBT}$ during the observation period, nearly one-half, $46.8 \%$ (95\% Cl, 45.3\%-48.4\%), received no CRC screening. After adjustment for other patient characteristics, receipt of a preventive health examination was strongly associated with FOBT adherence relative to no CRC screening (adjusted relative rate ratio $=11.16 ; 95 \% \mathrm{Cl}$, 9.61-12.96).

CONCLUSIONS Longitudinal adherence with FOBT screening was low in this insured population, potentially compromising its effectiveness in population CRC mortality reduction. Interventions to promote adherence may be necessary to achieve high effectiveness in population-based FOBT screening programs.

Ann Fam Med 2010;8:397-401. doi:10.1370/afm.1133.

\section{INTRODUCTION}

$\mathrm{P}$ ublic health organizations worldwide have endorsed colorectal (CRC) screening for adults aged 50 years and older. In randomized controlled trials, fecal occult blood test (FOBT) screening performed either annually or biennially reduced both CRC incidence and mortality. ${ }^{1-4}$ FOBT is relatively easy to perform, safe, and inexpensive, making it an appealing means of population screening. Many industrialized countries have national or regional CRC screening programs based on FOBT. ${ }^{5}$ Although colonoscopy is now more widely used than FOBT in the United States, ${ }^{6}$ many patients continue to choose FOBT as their CRC screening strategy, and FOBT plays a central role in the CRC screening programs of US managed care plans and within underserved or rural populations that lack access to sigmoidoscopy or colonoscopy.

The US Preventive Services Task Force recently reported that the efficacy of high-sensitivity annual FOBT screening in terms of life-years gained is essentially equivalent to a strategy of colonoscopy performed alone every 10 years. ${ }^{7}$ Yet an FOBT strategy may be more cost-efficient, because it would require substantially fewer total colonoscopies. On the 
other hand, statistical models suggest that an FOBT strategy may fall short if a large proportion of patients do not adhere to repeated screenings.

In 2 randomized trials of FOBT screening, patient adherence with regular screening was relatively high, exceeding $75 \%$ during the 13 -year study period of the Minnesota Colon Cancer Control Study. ${ }^{1,4}$ The degree to which the general population adheres to regular FOBT screening is unknown, however. Among health plan enrollees who had previously engaged in FOBT screening, we assessed subsequent adherence with repeated CRC screening with or without a FOBT. We also identified patient-level predictors of adherence with FOBT screening to assist in targeting potential interventions to improve adherence.

\section{METHODS}

\section{Participants and Setting}

Participants were enrolled in Group Health Cooperative, a mixed-model, integrated health plan in Washington State, where approximately 350,000 enrollees receive care from a multispecialty group practice. The Group Health Cooperative Human Subjects Review Committee approved the study methods.

From population-based automated health care data, we identified a sample of patients who were aged 52 to 78 years on January 1, 2002, and eligible for CRC screening in 2002-2003 based on previously described enrollment and eligibility criteria. ${ }^{8,9}$ From the sample, we identified patients who completed a 3-card FOBT test (Hemoccult II SENSA, Beckman Coulter, Fullerton, California) during a baseline period (2000-2001) and were enrolled during the subsequent 2-year observation study period (2002-2003) for assessment of adherence with biennial FOBT screening. Patients were excluded if they had an abnormal FOBT finding during the baseline period or the 3 previous years (1997-2001).

In 2002-2003, the health plan recommended CRC screening for adults aged 50 years and older by means of biennial FOBT and sigmoidoscopy every 10 years, which is consistent with the 2002 recommendations of the US Preventive Services Task Force. ${ }^{10}$ The guideline allowed for alternative strategies based on patientphysician decisions (eg, annual FOBT or screening colonoscopy), and the plan publicized its recommendations through print (eg, pamphlets in waiting rooms) and electronic (eg, Web sites for patients and physicians) media. The plan processes all 3-card FOBTs within central laboratories, which record results in electronic databases. Although the plan used an automated system to notify primary care physicians when patients did not receive timely colonoscopy after abnormal FOBT results, ${ }^{11}$ it did not provide patients or physician reminders about CRC screening. Although patients could conceivably have completed FOBT outside the plan, they receive most medical care within the integrated system.

\section{CRC Screening Adherence}

We analyzed automated procedure and laboratory data to ascertain completion of CRC tests during the baseline and observation periods, including FOBTs, flexible sigmoidoscopies, colonoscopies, and double-contrast barium enemas. We defined patients as adherent with biennial FOBT recommendations if the laboratory data signified completion of a 3-card FOBT in 2002-2003. We categorized patients into 3 mutually exclusive categories based on test use in 2002-2003: (1) nonadherent with any CRC tests, (2) adherent with FOBT with or without other CRC tests, and (3) adherent with 1 or more CRC tests without FOBT. We could not definitively distinguish tests performed for screening from those performed for diagnostic purposes.

\section{Covariates}

We classified patients by age, sex, and comorbidity based on an automated version of the Charlson comorbidity index. ${ }^{12}$ We counted the total number of primary care and non-primary care visits in 2002-2003. We assessed primary care visits because primary care physicians are chiefly responsible for providing preventive services within the plan. Using previously described visit and diagnostic codes ${ }^{8,13}$ we ascertained receipt of 1 or more preventive health examinations during the observation period (2002-2003). We assessed receipt of the preventive health examination because this examination may be an opportunity for clinicians to encourage patient adherence with ongoing FOBT screening. ${ }^{8}$

\section{Analyses}

We performed descriptive and bivariate analyses to describe the distribution of patient characteristics and their association with CRC testing during the observation period (received FOBT vs received other CRC test vs received no CRC test). Using this 3 -category outcome as the dependent variable (with the latter category as reference), we performed multinomial logistic regression to estimate the adjusted relative rate ratio (RRR) of CRC screening associated with a patient characteristic. Covariates included age (continuous), sex, Charlson comorbidity index $(0,1,2, \geq 3)$, primary care and non-primary care visits (both continuous), and binary variables signifying whether patients received a preventive health examination during the observation period. To account for within-practice correlations, all standard errors and confidence intervals were based on sandwich variance estimates for clus- 


\begin{tabular}{|c|c|}
\hline Outcome & $\operatorname{RRR}^{a}(95 \% \mathrm{Cl})$ \\
\hline \multicolumn{2}{|l|}{ Adherent with FOBT vs no screening } \\
\hline Age, year & $1.02(1.02-1.03)$ \\
\hline Male sex & $1.44(1.31-1.58)$ \\
\hline Charlson Comorbidity Index & $1.0(\mathrm{ref})^{\mathrm{b}}$ \\
\hline 0 & $0.78(0.68-0.88)$ \\
\hline 1 & $0.93(0.76-1.13)$ \\
\hline 2 & $0.53(0.40-0.69)$ \\
\hline \multicolumn{2}{|l|}{$\geq 3$} \\
\hline No. of primary care visits (2002-2003) & $1.01(1.00-1.02)$ \\
\hline No. of non-primary care visits (2002-2003) & $1.00(0.99-1.01)$ \\
\hline $\begin{array}{l}\text { Preventive health examination (PHE) during } \\
\text { observation period (2002-2003) }\end{array}$ & $11.16(9.61-12.96)$ \\
\hline \multicolumn{2}{|l|}{$\begin{array}{l}\text { Adherent with CRC tests other than } \\
\text { FOBT vs no screening }\end{array}$} \\
\hline Age, year & $0.98(0.97-0.99)$ \\
\hline Male sex & $1.03(0.88-1.21)$ \\
\hline Charlson Comorbidity Index & $1.0(\mathrm{ref})^{\mathrm{b}}$ \\
\hline 0 & $0.80(0.65-1.00)$ \\
\hline 1 & $0.68(0.50-0.92)$ \\
\hline 2 & $0.63(0.42-0.96)$ \\
\hline \multicolumn{2}{|l|}{$\geq 3$} \\
\hline No. of primary care visits (2002-2003) & $1.01(1.00-1.02)$ \\
\hline No. of non-primary care visits (2002-2003) & $1.02(1.01-1.03)$ \\
\hline PHE during observation period (2002-2003) & $2.36(2.02-2.75)$ \\
\hline \multicolumn{2}{|c|}{$\begin{array}{l}\mathrm{CRC}=\text { colorectal cancer; } \mathrm{FOBT}=\text { fecal occult blood test; ref }=\text { reference cat- } \\
\text { egory; } \mathrm{PHE}=\text { preventive health examination; } \mathrm{RRR}=\text { relative rate ratio. }\end{array}$} \\
\hline \multicolumn{2}{|c|}{$\begin{array}{l}\text { a Relative rate ratio of CRC screening outcome compared with no CRC screen- } \\
\text { ing associated with change in covariate value. } \\
\text { b P for linear trend }<.001 \text {. }\end{array}$} \\
\hline
\end{tabular}

preventive health examination in 2002-2003 (adjusted $\mathrm{RRR}=11.16$; 95\% CI, 9.61-12.96).

A different pattern of patient characteristics was associated with receipt of other CRC tests without FOBT (Table 2). Among patients who did not receive a FOBT, relative rates of CRC test completion were significantly increased for patients who were younger, had lesser comorbidity, and received greater numbers of primary care and non-primary care visits. As with FOBT adherence, receipt of a preventive health examination during the observation period was significantly associated with completing CRC tests other than FOBT (adjusted RRR $=2.37$; 95\% CI, 2.02-2.77).

\section{DISCUSSION}

The US Multi-Society Task Force on Colorectal Cancer stated that the effectiveness of an FOBT screening program will hinge on whether patients adhere to regular screening. ${ }^{14}$ Similarly, the US Preventive Services Task Force observed that, for the individual patient, "adherence to a screening regimen will be more important in terms of life-years gained than will the particular regimen selected."15 Within an insured population served by an integrated health plan, approximately one-half of patients who initiated FOBT screening during a baseline period adhered with FOBT or another method of CRC screening during the ensuing 2-year period. Although several guidelines now recommend annual FOBT screening, ${ }^{14-16}$ our findings suggest that long-term adherence with annual FOBT screening would be low in our study population, potentially compromising the effectiveness of the program to reduce population CRC mortality.

High national rates of mammography and Papanicolaou smear screening suggest that an annual or biennial testing interval by itself does not preclude widespread uptake of a cancer screening test. Although the plan officially recommended FOBT screening during the study period, it had no systematic program to remind patients or physicians about the need for repeated screening. In contrast, since 1986, the health plan has operated a highly successful breast cancer screening program that tracks mammography utilization and provides mailed reminders to women and periodic reports to primary care physicians. ${ }^{17}$ Similar programmatic interventions could conceivably achieve high FOBT adherence rates. ${ }^{18,19}$

Patients who received a preventive health examination were much more likely to adhere to FOBT screening than patients who did not. During visits dedicated to prevention, physicians may be more likely to recognize that an FOBT is due and to devote time to counseling patients regarding barriers to adherence or alternative methods of CRC screening. ${ }^{8}$ In contrast, physicians may find it difficult to address the topic of CRC screening during primary care visits for acute or chronic illness.

In our study, men were significantly more likely than women to adhere with ongoing FOBT screening. Among national samples, women have had greater prevalence of FOBT use than men. ${ }^{20-22}$ Thus, although women may be more likely to initiate FOBT use, our findings suggest that men may be more likely to continue with FOBT once initiated.

Older age was associated with ongoing adherence with FOBT, whereas younger age was associated with subsequent use of CRC tests other than FOBT. Health plan physicians may consider older patients to be at higher risk of complications from sigmoidoscopy or colonoscopy so recommend continuing with FOBT. National survey data suggest, however, that older age is associated with greater use of all CRC screening methods. $^{23}$

Several study limitations warrant consideration, including uncertain generalizability outside the health 
plan. Data also derive from 2000 to 2003, and patient and physician awareness of CRC screening guidelines may have changed since the time of the study. We also acknowledge that associations between patient factors and FOBT adherence may not be causal. Furthermore, we could not definitively distinguish screening from diagnostic tests and lacked data on potentially important variables (eg, socioeconomic status).

In a large US health plan, nearly one-half of patients who initiated biennial FOBT screening did not adhere to subsequent CRC screening in the ensuing 2-year period, which may compromise the effectiveness of the screening endeavor. CRC screening programs based on stool testing may need to invest in interventions to foster high population adherence with regular screening.

To read or post commentaries in response to this article, see it online at http://www.annfammed.org/cgi/content/full/8/5/397.

Submitted September 11, 2009; submitted, revised, December 17, 2009; accepted January 5, 2010.

Key words: Patient compliance; colorectal cancer; mass screening; population-based studies; health promotion; preventive health services; health care delivery; health services research

Funding support: Supported by grants from the National Cancer Institute, U19CA79689 and KO5 CA 104699 (J.G.E.), and American Cancer Society Mentored Research Scholars Grant, MRSGT-05-214-01-CPPB (J.J.F.). This research was funded in part by an $\mathrm{HMO}$ Cancer Research Network (CRN) pilot grant.

The CRN consists of the research programs, enrollee populations, and databases of the 14 health maintenance organization (HMO) members of the HMO Research Network. The overall goal of the CRN is to conduct collaborative research to determine the effectiveness of preventive, curative, and supportive interventions for major cancers that span the natural history of those cancers among diverse populations and health systems. The 14 health plans, with nearly 11 million enrollees are distinguished by their long-standing commitment to prevention and research and to collaboration among themselves and with affiliated academic institutions.

\section{References}

1. Mandel JS, Bond JH, Church TR, et al. Reducing mortality from colorectal cancer by screening for fecal occult blood. Minnesota Colon Cancer Control Study. N Engl J Med. 1993;328(19):1365-1371.

2. Mandel JS, Church TR, Bond JH, et al. The effect of fecal occultblood screening on the incidence of colorectal cancer. N Engl J Med. 2000;343(22):1603-1607.

3. Hardcastle JD, Chamberlain JO, Robinson MH, et al. Randomised controlled trial of faecal-occult-blood screening for colorectal cancer. Lancet. 1996;348(9040):1472-1477.

4. Kronborg O, Fenger C, Olsen J, Jørgensen OD, Søndergaard O. Randomised study of screening for colorectal cancer with faecal-occultblood test. Lancet. 1996;348(9040):1467-1471.

5. Inventory of Colorectal Cancer Screening Activities in International Cancer Screening Network (ICSN) Countries. May 2008. National Cancer Institute Web Site. http://appliedresearch.cancer.gov/icsn/ colorectal/screening.html. Accessed Jun 1, 2009.
6. Meissner HI, Breen N, Klabunde CN, Vernon SW. Patterns of colorectal cancer screening uptake among men and women in the United States. Cancer Epidemiol Biomarkers Prev. 2006;15(2):389-394

7. Zauber AG, Lansdorp-Vogelaar I, Knudsen AB, Wilschut J, van Ballegooijen M, Kuntz KM. Evaluating test strategies for colorectal cancer screening: a decision analysis for the U.S. Preventive Services Task Force. Ann Intern Med. 2008;149(9):659-669.

8. Fenton JJ, Cai Y, Weiss NS, et al. Delivery of cancer screening: how important is the preventive health examination? Arch Intern Med. 2007;167(6):580-585.

9. Fenton JJ, Franks P, Reid RJ, Elmore JG, Baldwin LM. Continuity of care and cancer screening among health plan enrollees. Med Care. 2008;46(1):58-62.

10. Pignone M, Rich M, Teutsch SM, Berg AO, Lohr KN. Screening for colorectal cancer in adults at average risk: a summary of the evidence for the US Preventive Services Task Force. Ann Intern Med. 2002;137(2):132-141.

11. Miglioretti DL, Rutter CM, Bradford SC, et al. Improvement in the diagnostic evaluation of a positive fecal occult blood test in an integrated health care organization. Med Care. 2008;46(9)(Suppl 1): S91-S96.

12. Deyo RA, Cherkin DC, Ciol MA. Adapting a clinical comorbidity index for use with ICD-9-CM administrative databases. J Clin Epidemiol. 1992;45(6):613-619.

13. Tao G, Zhang P, Li Q. Services provided to nonpregnant women during general medical and gynecologic examinations in the United States. Am J Prev Med. 2001;21(4):291-297.

14. Levin B, Lieberman DA, McFarland B, et al. American Cancer Society Colorectal Cancer Advisory Group; US Multi-Society Task Force; American College of Radiology Colon Cancer Committee. Screening and surveillance for the early detection of colorectal cancer and adenomatous polyps, 2008: a joint guideline from the American Cancer Society, the US Multi-Society Task Force on Colorectal Cancer, and the American College of Radiology. CA Cancer J Clin. 2008;58(3):130-160.

15. U.S. Preventive Services Task Force. Screening for colorectal cancer: Recommendation statement. Agency for Healthcare Research and Quality Web site. http://www.ahrq.gov/clinic/uspstf08/colocancer/ colors.htm. Accessed Jun 1, 2009.

16. Smith RA, Cokkinides V, Brawley OW. Cancer screening in the United States, 2008: a review of current American Cancer Society guidelines and cancer screening issues. CA Cancer J Clin. 2008;58(3):161-179.

17. Taplin SH, Ichikawa L, Buist DS, Seger D, White E. Evaluating organized breast cancer screening implementation: the prevention of late stage disease? Cancer Epidemiol Biomarkers Prev. 2004;13(2):225-234.

18. Church TR, Yeazel MW, Jones RM, et al. A randomized trial of direct mailing of fecal occult blood tests to increase colorectal cancer screening. J Natl Cancer Inst. 2004;96(10):770-780.

19. Klabunde CN, Lanier D, Breslau ES, et al. Improving colorectal cancer screening in primary care practice: innovative strategies and future directions. J Gen Intern Med. 2007;22(8):1195-1205.

20. McQueen A, Vernon SW, Meissner HI, Klabunde CN, Rakowski W. Are there gender differences in colorectal cancer test use prevalence and correlates? Cancer Epidemiol Biomarkers Prev. 2006;15(4):782-791.

21. Seeff LC, Nadel MR, Klabunde CN, et al. Patterns and predictors of colorectal cancer test use in the adult U.S. population. Cancer. 2004;100(10):2093-2103

22. Fenton JJ, Cai Y, Green P, Beckett LA, Franks P, Baldwin LM. Trends in colorectal cancer testing among Medicare subpopulations. Am J Prev Med. 2008;35(3):194-202.

23. Joseph DA, Rim SH, Seeff LC; Centers for Disease Control and Prevention (CDC). Use of colorectal cancer tests-United States, 2002, 2004, and 2006. MMWR Morb Mortal Wkly Rep. 2008;57(10): 253-258. 